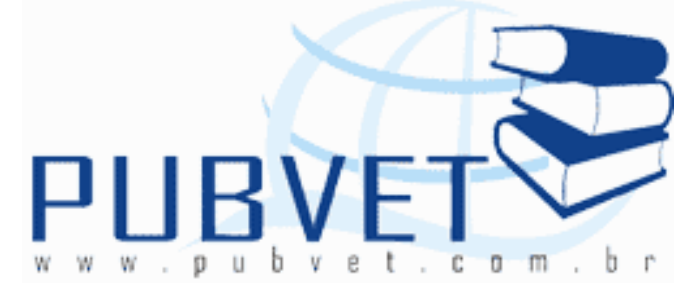

PUBVET, Publicações em Medicina Veterinária e Zootecnia.

\title{
Características fenotípicas de filhotes após consumo involuntário de etanol em rata da linhagem Wistar durante a prenhez
}

Karina Bianca Messias ${ }^{1}$, Gabriela Camila Barreto ${ }^{1}$, Steffanie Nunes Martins Brito $^{1}$, Ricardo S. Augusto ${ }^{1}$ e Otávio Augusto Martins ${ }^{1,2}$

${ }^{1}$ Faculdades Integradas Regionais de Avaré, Fundação Regional Educacional de Avaré, Avaré, São Paulo, Brasil.

${ }^{2}$ Faculdade de Medicina Veterinária e Zootecnia, Universidade Estadual Paulista, Botucatu, São Paulo, Brasil.

\section{Resumo}

O presente trabalho aborda o consumo de bebidas alcoólicas em mulheres no período gestacional. O principal objetivo foi descrever as características fenotípicas dos filhotes e analisar o desenvolvimento dos filhotes no Período Hiporresponsivo ao Estresse (SHRP). Foram utilizadas ratas fêmeas adultas da linhagem Wistar. As ratas, após a fertilização, foram acompanhadas durante o período gestacional e após o nascimento dos filhotes. As ratas, durante a prenhez e após o nascimento dos filhotes, foram mantidas sob uma dieta nutricional a base de ração e álcool a $10 \%$ ad libitium. Os resultados demonstraram que os filhotes provenientes de mãe que consumiu involuntariamente o etanol a $10 \%$ apresentaram diferenças fenotípicas. Com base nos resultados obtidos, conclui-se que o etanol administrado durante a gestação e após o nascimento, pode ocasionar sérios danos para o feto, como 
MESSIAS, K.B. et al. Características fenotípicas de filhotes após consumo involuntário de etanol em rata da linhagem Wistar durante a prenhez. PUBVET, Londrina, V. 7, N. 2, Ed. 225, Art. 1492, 2013.

prejuízos maturacionais entre outros danos caracterizados como Síndrome Alcoólica Fetal (SAF).

Palavras-chave: SHRP; Alcoolismo Feminino; Síndrome Alcoólica Fetal.

\title{
Phenotypic characteristics of pups after involuntary consumption of ethanol in Wistar rat during pregnancy
}

\begin{abstract}
This paper discusses alcohol consumption in women during pregnancy. The main objective was to describe the phenotypic characteristics of the pups and analyze the development of the pups in the stress hyporesponsive period (SHRP). We used adult female rats of Wistar strain. The rats, after fertilization, were followed during pregnancy and after the birth of the puppies. The rats during pregnancy and after the birth of the puppies were kept in a nutritional diet based in food and alcohol at $10 \%$ ad libitium. The results showed that the pups from the mother who unwittingly consumed $10 \%$ ethanol showed phenotypic differences. Based on these results, we conclude that ethanol administered during pregnancy and after birth, can cause serious damage to the fetus, as maturational losses among other damage characterized as Fetal Alcohol Syndrome (FAS).
\end{abstract}

Keywords: SHRP; Female Alcoholism, Fetal Alcohol Syndrome.

\section{INTRODUÇÃO}

O alcoolismo é uma das mais graves enfermidades mundiais, sendo que $90 \%$ das pessoas ingerem algum tipo de bebida alcoólica. Seu uso indevido é um dos fatores que contribuem para a diminuição da saúde mundial, é a terceira doença que mais mata no mundo, só perdendo para o câncer e as doenças do coração, estando intimamente ligada a problemas relacionados ao campo social, como desordem pública, problemas familiares do tipo, conflitos conjugais e divórcio, abuso de menores, problemas financeiros, interpessoais, 
MESSIAS, K.B. et al. Características fenotípicas de filhotes após consumo involuntário de etanol em rata da linhagem Wistar durante a prenhez. PUBVET, Londrina, V. 7, N. 2, Ed. 225, Art. 1492, 2013.

ocupacionais, dificuldades educacionais e custos sociais (MELONI \& LARANJEIRA, 2008). Distinguidas dos problemas sociais, as categorias dos problemas á saúde relacionados ao alcoolismo podemos destacar brevemente seus malefícios, como ataque cardíaco, doenças respiratórias, enfisema, câncer, impotência sexual, alterações na memória, perda do autocontrole, gota, rompimento das veias, danos no fígado, rins e estômago, cirrose hepática, úlceras, gastrites, irritabilidade, dor de cabeça, insônia, ansiedade, agitação e outros (BARBOSA et al., 2009).

A palavra alcoolismo é utilizada para designar uma conseqüência onde ocorre a ingestão de etanol que é o principal componente das bebidas alcoólicas, sendo que o alcoólatra é o bebedor excessivo, cuja dependência ao álcool chegou ao ponto de Ihe criar transtornos em sua saúde física, ou mental, nas suas relações interpessoais e na sua função social e econômica e que por isso, necessitando então de tratamento (BARBOSA et al., 2009).

O alcoolismo começa com doses pequenas, por um simples hábito, onde o usuário vai se tornando cada vez mais tolerante e dependente da bebida, chegando então no caso de abstinência e perda de controle. Entende-se por tolerância, a necessidade de doses cada vez maiores de álcool, para que exerça o mesmo efeito, e por síndrome de abstinência um quadro de desconforto físico ou psíquico da diminuição, ou até mesmo na suspensão do consumo etílico (GLIGLIOTTI \& BESSA, 2004).

Atualmente o uso abusivo de álcool na adolescência tem nos chamado mais a atenção, tornando - se a preocupação da saúde pública. Estudos epidemiológicos referem que o consumo de bebidas alcoólicas tem início em idades cada vez mais precoces (VILELA et al., 2011).

O alcoolismo na adolescência está associado às principais causas de mortalidades, como suicídios, homicídios, acidentes de trânsito, além de aumentar a probabilidade de doenças sexualmente transmissíveis (VILELA et al., 2011).

Estudos indicam que $80 \%$ dos adolescentes que abusam das bebidas alcoólicas apresentam algum tipo de psicopatologia, tais como, perturbação da 
MESSIAS, K.B. et al. Características fenotípicas de filhotes após consumo involuntário de etanol em rata da linhagem Wistar durante a prenhez. PUBVET, Londrina, V. 7, N. 2, Ed. 225, Art. 1492, 2013.

conduta e/ou perturbação depressiva, sendo que muitas variáveis podem influenciar o jovem ao consumo de bebidas alcoólicas, que é o caso da psicopatologia parental, ou seja, o ambiente e o contexto sócio familiar podem estar contribuindo para um impacto maior ao longo da adolescência, no entanto os sintomas depressivos na infância predispõem na ingestão de álcool (VILELA et al., 2011).

MESSAS \& FILHO (2004), apontam estudos epidemiológicos e moleculares sobre a presença de fatores hereditários no gênese do abuso ou dependência do álcool, sendo que tanto o abuso, quanto a dependência da bebida seria resultante de uma complexa interação de fatores genéticos, psicossociais e culturais.

As mulheres iniciam seus hábitos de beber mais tardiamente comparando-as aos homens, mas os problemas relacionados ao uso e abuso de álcool são mais precoces nas mulheres. As mulheres têm maior biodisponibilidade ao álcool do que os homens, ou seja, as mesmas concentrações de etanol ingerido em ambos os sexos serão maiores na mulher, deixando-a mais explicitamente embriagadas. Isso se explica pelo fato de que as mulheres possuem uma proporção de gordura corpórea maior, uma menor quantidade de água e uma baixa atividade da enzima álcool desidrogenase, fazendo com que o organismo da mulher seja de maior absorção de etanol do que o organismo masculino (PESSOA, 2009).

Sabe-se que o álcool consumido por mulheres, e ingerido na gravidez, provoca sérios problemas de saúde, tanto para a gestante, quanto para o feto, a embriotoxicidade e teratogenicidade fetal. Isso se explica, pois os mecanismos fisiológicos de nutrição fetal se inicia a partir do momento da fecundação, constituindo assim uma integração de dois seres em um mesmo organismo, tornando-se suscetível a todas influências do meio ou que venham a envolvê-lo (FABBRI, 2001).

As influências fetais prevalecem a do organismo materno, interpretado como fonte nutritiva, onde as alterações farão presentes do desenvolvimento embrionário (ROSSI et al., 2012). 
MESSIAS, K.B. et al. Características fenotípicas de filhotes após consumo involuntário de etanol em rata da linhagem Wistar durante a prenhez. PUBVET, Londrina, V. 7, N. 2, Ed. 225, Art. 1492, 2013.

Durante a gestação, a circulação sanguínea é responsável pelo transporte de nutrientes para o feto, sendo assim a exposição ao álcool tem efeitos complexos ao passar pela placenta, que tem a função relacionada tanto a nutrição, quanto da eliminação de resíduos fetais, podendo vir a interferir no desenvolvimento fetal (FABBRI, 2001).

O álcool ingerido pela gestante irá cruzar a barreira placentária, indo para o líquido amniótico, chegando até o feto, que receberá as mesmas concentrações de álcool que a gestante, sendo desta maneira, a exposição fetal é maior, devido ao baixo metabolismo e a eliminação de resíduos serem mais lentos, fazendo como que o líquido amniótico mantenha-se impregnado de álcool não modificado pela ausência de enzimas suficientes para fazer a degradação destas substâncias (FABBRI, 2001).

O mecanismo de ação do etanol parece ser muito, e a isoenzima do álcool - desidrogenase podem influenciar a evolução fetal alterando - a, incluindo efeitos no metabolismo e alteração da função endócrina fetal, transporte de aminoácido pela placenta, redução da absorção de nutrientes, por intermédio da mucosa intestinal e alterações no metabolismo hepático materno (FABBRI, 2001).

Em vista das manifestações nocivas provocadas por alterações no organismo materno e pelo comprometimento do fluxo sanguíneo placentário, pode-se considerar a ação exercida pelo álcool na embriogênese ou na fatogênese, interligada á sua absorção (ROSSI et al., 2012 ).

O etanol além de ter efeitos diretos sobre vários fatores de crescimento celular, inibindo a proliferação de certos tecidos, também induz a formação de radicais livres de oxigênio que são capazes de danificar proteínas e lipídeos celulares, aumentando a apoptose e prejudicando a organogênese, inibindo a síntese de ácido retinóico, substância reguladora do desenvolvimento embrionário (ROSSI et al., 2012 ).

A evolução fetal pode estar associada, não somente pelo consumo de álcool pela mãe, mas também pela deficiência nutricional intra-uterina, 
MESSIAS, K.B. et al. Características fenotípicas de filhotes após consumo involuntário de etanol em rata da linhagem Wistar durante a prenhez. PUBVET, Londrina, V. 7, N. 2, Ed. 225, Art. 1492, 2013.

podendo induzir as más formações, até a teratogênese, que varia seus efeitos dependendo do nível a exposição intra-uterina (FABBRI, 2001).

As teratogênicas relacionadas ao consumo de álcool durante a gestação são denominadas de Síndrome Alcoólica Fetal (SAF), podendo ser diagnosticado mais facilmente no período após o neonatal, quando se associam ao retardo mental e o déficit (FABBRI, 2001).

O consumo de álcool na gestação é responsável por inúmeros abortos, fatores comprometedores do parto, com risco de infecções, deslocamento prematuro da placenta, hipertonia uterina, prematuridade do trabalho de parto e líquido amniótico meconial (FABBRI, 2001).

A exposição do álcool pode continuar no período pós-natal, pois o álcool está presente no leite materno em níveis idênticos aos sanguíneos, o que pode ser muito significativo nos efeitos em relação nutricional e emocional (ROSSI et al., 2012).

As preocupações relacionadas ao leite materno envolve a quantidade de leite disponível que será diminuída se a mamada for precedida por consumo de álcool, a produção de prolactina e ocitocina reduzidas pela sucção diminuída e a própria capacidade de sucção por parte do bebê com SAF é menor (ROSSI et al., 2012).

Quando as más formações clínicas não são completas, sem os sinais de dimorfismo facial, a síndrome é chamada de Efeito Alcoólico Fetal (EAF) (ROSSI et al., 2012).

A principal característica da fase de desenvolvimento pós-natal do sistema de estresse é denominado Período Hiporresponsivo ao Estresse (SHRP, do inglês stress hiporesponsive period), influências causadas pelas variações do cuidado materno, responsáveis por inibir as respostas endócrinas ao estresse de filhotes após o nascimento, esses por sua vez no decorrer de seu desenvolvimento, podem ativar o sistema periférico e central que são responsivos ao estresse (KREMER, 2007).

O SHRP é crítico para o desenvolvimento neural, em que os processos vitais como migração, divisão, diferenciação, crescimento e morte celular 
prevalecem no cérebro, além de que sistemas inibitórios e excitatórios de neurotransmissor alcançam a maturidade. Portanto, durante o período SHRP, principalmente nas duas primeiras semanas de vida pós - natal, tanto os estímulos aparentemente inofensivos, quanto os estímulos estressores, induzem alterações comportamentais e endócrinos na vida adulta (KREMER, 2007).

Animais em experimentos científicos são utilizados há séculos, tendo a finalidade de novos conhecimentos e benefícios para a saúde, mas apenas recentemente a importância do modelo animal para resultados em experimento foi reconhecida. Desta forma surgiu a ciência em animais de laboratório, sendo o modelo mais utilizado os em ratos, isso por que além de serem de porte menores podendo ser mantidos em lugares que ocupem pouco espaço, é também de fácil reprodução, evitando assim danos á espécie (FRAJBLAT et al., 2008).

Com base neste estudo, os objetivos do presente trabalho consistem em (a) descrever as características fenotípicas dos filhotes após o consumo involuntário de etanol em rata mãe da linhagem Wistar durante a prenhez e (b) analisar o desenvolvimento dos filhotes no Período Hiporresponsivo ao Estresse (SHRP).

\section{MATERIAL E MÉTODOS}

\section{Animais}

Os ratos da linhagem Wistar foram provenientes do Biotério das Faculdades Integradas Regionais de Avaré (FIRA), Fundação Regional Educacional de Avaré (FREA), São Paulo, Brasil.

Foram formados quatro casais da linhagem Wistar. As fêmeas adultas, após a fertilização, foram divididas em dois tratamentos experimentais (Controle- C e Consumo Involuntário de Etanol - CIE). As fêmeas adultas foram acompanhadas durante o período gestacional e após o nascimento dos filhotes. As fêmeas prenhas do tratamento CIE receberam ração normal e 
MESSIAS, K.B. et al. Características fenotípicas de filhotes após consumo involuntário de etanol em rata da linhagem Wistar durante a prenhez. PUBVET, Londrina, V. 7, N. 2, Ed. 225, Art. 1492, 2013.

solução de etanol a $10 \%$; e as fêmeas C receberam ração normal e água potável.

O dia do nascimento foi estipulado o dia zero, quando a ninhada foi padronizada com oito filhotes. Os filhotes controle e os do tratamento CIE foram observados no período hiporresponsivo ao estresse (SHRP). O alimento dos filhotes (C e CIE) no SHRP é praticamente o leite da rata mãe.

O protocolo experimental seguiu os princípios éticos em pesquisa animal adotado pelo Colégio Brasileiro de Experimentação Animal (COBEA).

\section{Consumo involuntário de etanol materno}

A análise do consumo involuntário da solução de etanol a $10 \%$ das ratas mães do tratamento CIE ocorreram em um dois períodos: (a) durante o período gestacional e (b) após o nascimento dos filhotes.

\section{Descrição das características fenotípicas dos filhotes}

As descrições das características fenotípicas dos filhotes das ninhadas dos tratamentos $\mathrm{C}$ e CIE ocorreram diariamente no Período Hiporresponsivo ao Estresse (SHRP), do $4^{\circ}$ ao $14^{\circ}$ dia de idade, sempre no mesmo horário.

As descrições das características fenotípicas foram (a) o aparecimento de pelos, (b) o descolamento total das orelhas, (c) a total abertura dos olhos e (e) o aparecimento das unhas. Os filhotes e as ratas mães foram acomodados com temperatura de $30^{\circ} \mathrm{C}$ e a umidade superior a $50 \%$.

Os animais foram manejados por único pesquisador do inicio ao fim da experimentação. As mãos do investigador foramlavadas, secas e esfregadas na maravalha de forro das caixas da ninhada, eliminando assim todos os odores que levassem a rejeição da mãe à prole. A sala de experimentação foi mantida isolada ao máximo de ruídos externos. 
MESSIAS, K.B. et al. Características fenotípicas de filhotes após consumo involuntário de etanol em rata da linhagem Wistar durante a prenhez. PUBVET, Londrina, V. 7, N. 2, Ed. 225, Art. 1492, 2013.

Análise do desenvolvimento da ninhada durante o período hiporresponsivo ao estresse (SHRP)

Foi mensurada a massa corpórea inicial, massa corpórea final e ganho de massa corpórea absoluta dos filhotes dos tratamentos C e CIE no período de $4^{\circ}$ a $14^{\circ}$ dia de após o nascimento da ninhada.

\section{Análise Estatística}

O estudo estatístico das variáveis foi realizado através da ANOVA e complementado com o teste de comparações múltiplas de Tukey para contraste entre médias dos tratamentos. Os resultados foram expressos em média \pm erro padrão da média. As conclusões estatísticas foram realizadas com $5 \%$ de significância. Detalhes a respeito da metodologia empregada podem ser encontrados em Banzatto \& Kronka (1989).

\section{RESULTADOS}

Consumo involuntário de etanol materno

A Tabela 1 mostra que o consumo da solução de etanol a $10 \%(\mathrm{~mL} / \mathrm{dia})$ pela rata mãe durante o período gestacional ou prenhez não apresentou diferença estatística significativa $(p=0,7529)$ comparada com o estágio após o nascimento dos filhotes no período hiporresponsivo ao estresse (SHRP).

Tabela 1. Consumo de solução de etanol a $10 \%(\mathrm{~mL} / \mathrm{dia})$ pela rata mãe durante o período gestacional ou prenhez e após o nascimento dos filhotes da linhagem Wistar. Análise estatística e teste de Tukey $(p<0,05)$.

\begin{tabular}{cc}
\hline Período & Média \pm erro padrão \\
\hline Gestacional ou prenhez & $58,65 \mathrm{~mL} / \mathrm{dia} \pm 5,44 \mathrm{a}^{1}$ \\
Após o nascimento dos filhotes & $50,15 \mathrm{~mL} / \mathrm{dia} \pm 10,40 \mathrm{a}$ \\
\hline${ }^{1}$ Teste de Tukey $(p=0,7529)$. &
\end{tabular}


MESSIAS, K.B. et al. Características fenotípicas de filhotes após consumo involuntário de etanol em rata da linhagem Wistar durante a prenhez. PUBVET, Londrina, V. 7, N. 2, Ed. 225, Art. 1492, 2013.

Descrição das características fenotípicas dos filhotes

Os filhotes $\mathrm{C}$ e do tratamento CIE apresentaram diferenças comparativas no desenvolvimento das características fenotípicas durante o SHRP (Figuras 1, $2,3$ e 4$)$.

O desenvolvimento total da orelha externa, aparecimento de pelos visíveis, detecção de dentes visíveis e olhos totalmente abertos em filhotes do tratamento CIE ocorreram tardiamente comparados com os filhotes C no SHRP. Também foram observados que os filhotes CIE eram menores comparados com os filhotes C (Tabela 2).

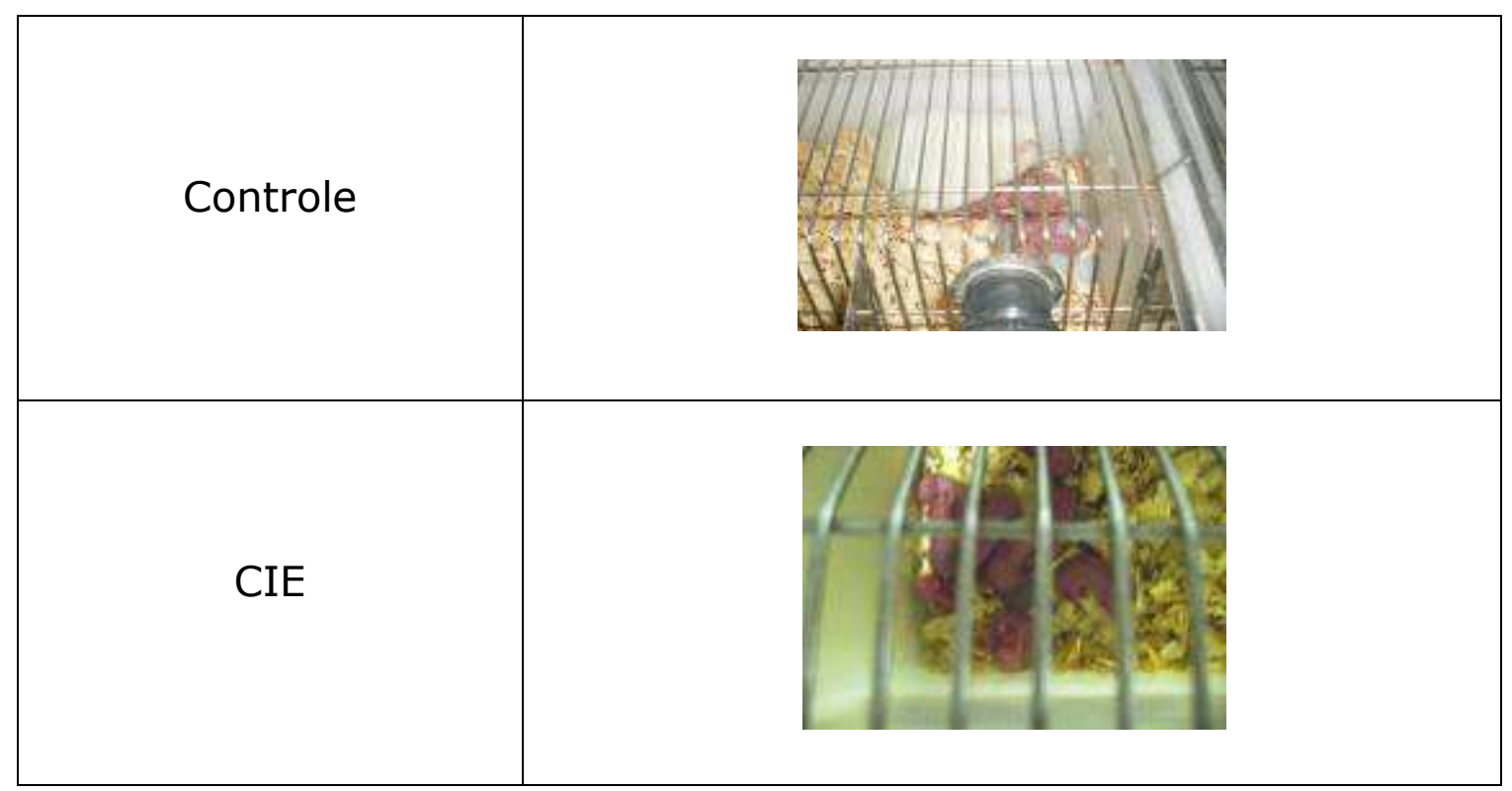

Figura 1. Filhotes controle e CIE no primeiro dia do período hiporresponsivo ao estresse (SHRP). 
MESSIAS, K.B. et al. Características fenotípicas de filhotes após consumo involuntário de etanol em rata da linhagem Wistar durante a prenhez. PUBVET, Londrina, V. 7, N. 2, Ed. 225, Art. 1492, 2013.

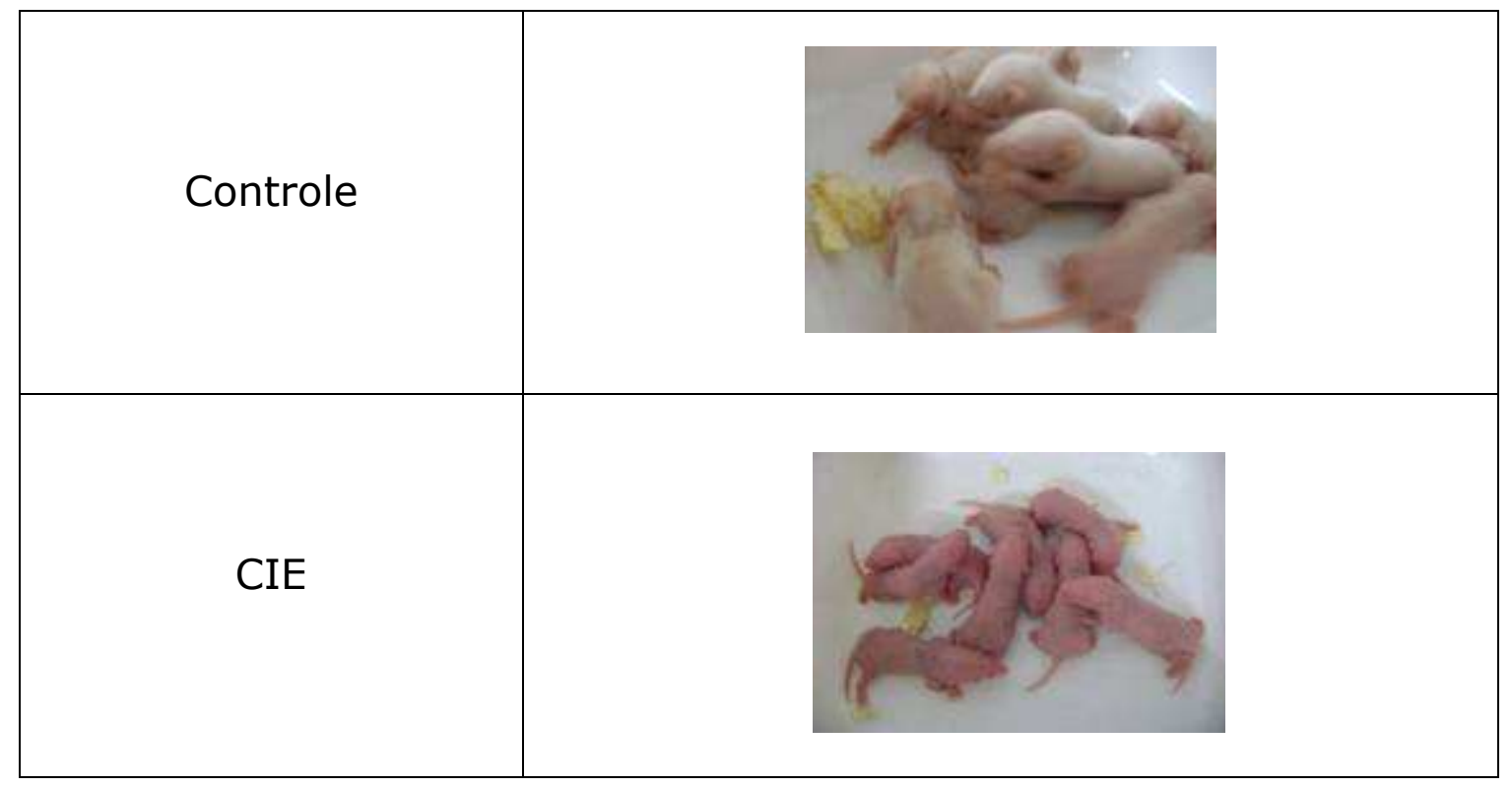

Figura 2. Filhotes controle e CIE no terceiro dia do período hiporresponsivo ao estresse (SHRP).

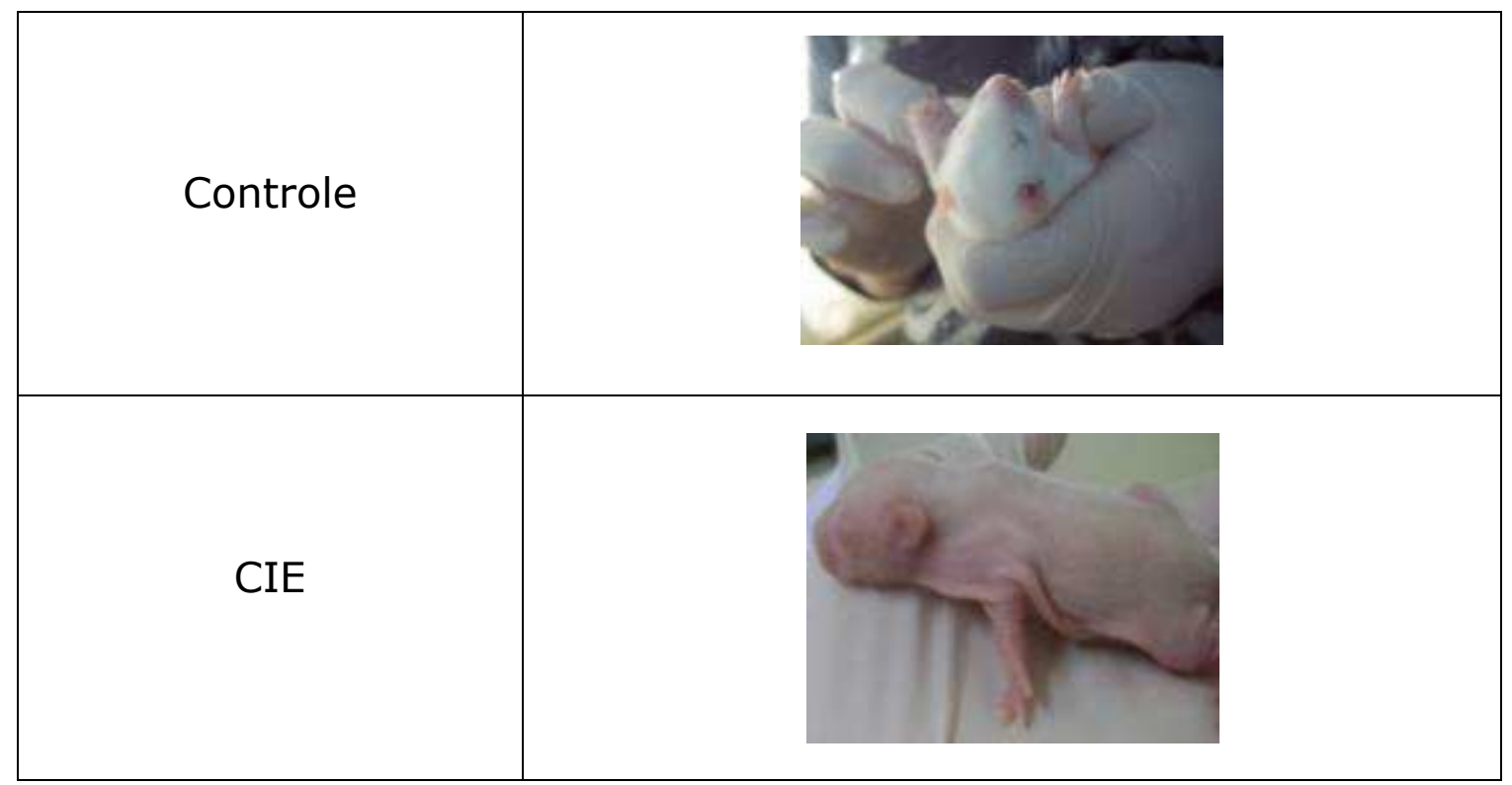

Figura 3. Filhotes controle e CIE no quinto dia do período hiporresponsivo ao estresse (SHRP). 


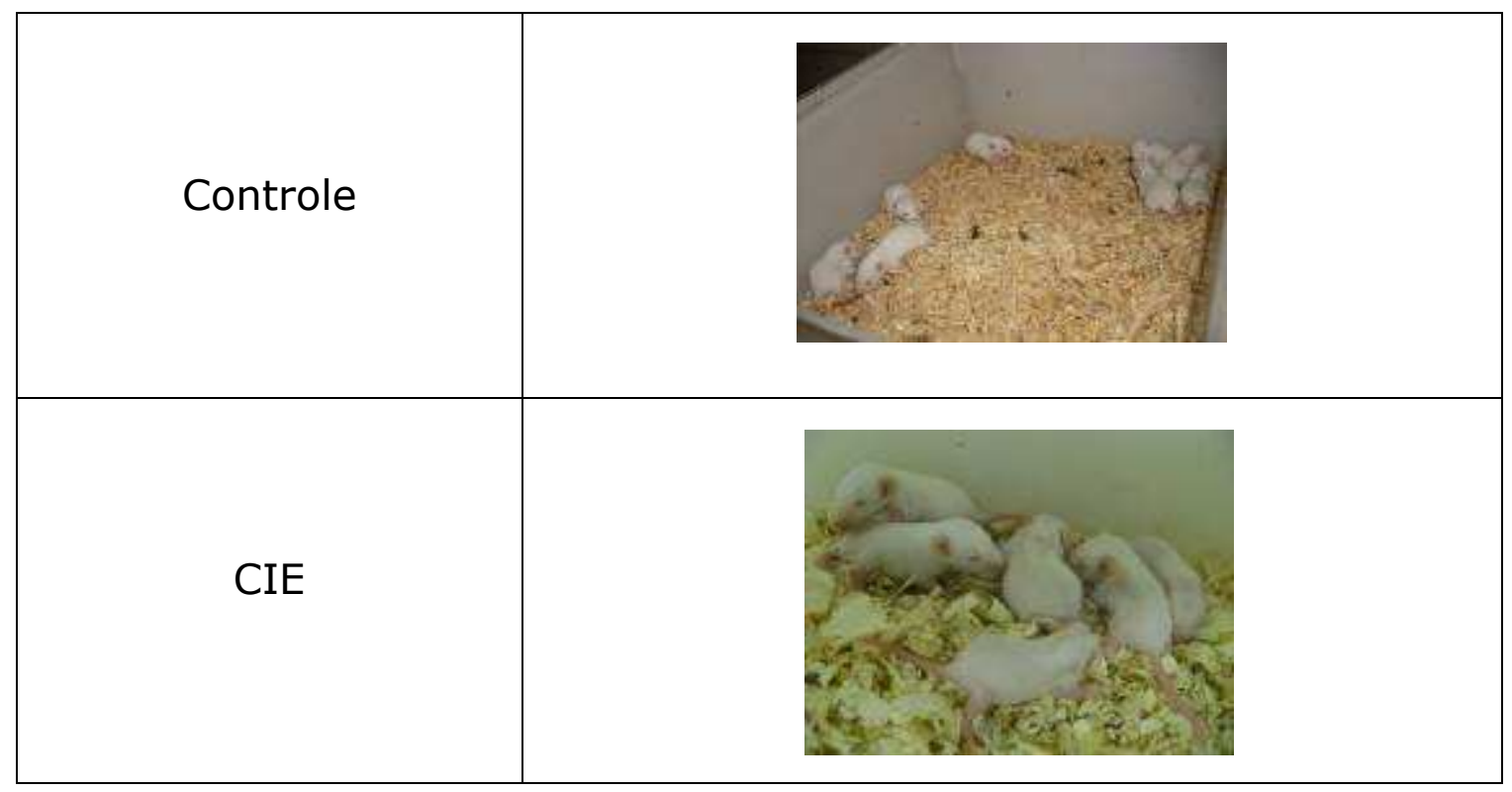

Figura 4. Filhotes controle e CIE no décimo dia do período hiporresponsivo ao estresse (SHRP).

Tabela 2. Características fenotípicas, em dias do período hiporresponsivo ao estresse (SHRP), dos filhotes C e CIE da linhagem Wistar.

\begin{tabular}{ccc}
\hline $\begin{array}{c}\text { Característica } \\
\text { fenotípica }\end{array}$ & \multicolumn{2}{c}{ Presença } \\
\cline { 2 - 3 } $\begin{array}{c}\text { Orelha externa } \\
\text { totalmente } \\
\text { desenvolvida }\end{array}$ & $5^{\circ}$ dia & $10^{\circ}$ dia \\
\hline $\begin{array}{c}\text { Pelos totalmente } \\
\text { visíveis }\end{array}$ & $3^{\circ}$ dia $-4^{\circ}$ dia \\
\hline Dentes visíveis & $4^{\circ}$ dia & $8^{\circ}$ dia \\
\hline $\begin{array}{c}\text { Olhos totalmente } \\
\text { abertos }\end{array}$ & $8^{\circ}$ dia & $8^{\circ}$ dia \\
\hline Filhotes menores & Ausência & $15^{\circ}$ dia \\
\hline
\end{tabular}


MESSIAS, K.B. et al. Características fenotípicas de filhotes após consumo involuntário de etanol em rata da linhagem Wistar durante a prenhez. PUBVET, Londrina, V. 7, N. 2, Ed. 225, Art. 1492, 2013.

Análise do desenvolvimento da ninhada durante o período hiporresponsivo ao estresse (SHRP)

A Tabela 3 demonstra a massa corpórea inicial da ninhada, a massa corpórea final e o ganho de massa corpórea absoluta foram distintos nas ninhadas C e CIE.

A média da massa corpórea da ninhada de ratos da linhagem Wistar do tratamento CIE apresentaram diferenças extremamente significativas $(p<0,0001)$ comparada com a ninhada $C$ no período de $4^{\circ}$ a $14^{\circ}$ dia após 0 nascimento (Tabela 4).

Tabela 3. Massa corpórea inicial (MCI), massa corpórea final (MCF) e ganho de massa corpórea absoluta (GMCA) da ninhada padronizada com oito filhotes de ratos da linhagem Wistar nos grupos controle (C) e consumo involuntário de etanol a $10 \%$ (CIE).

\begin{tabular}{cccc}
\hline \multirow{2}{*}{ Tratamentos } & \multicolumn{3}{c}{ Parâmetros } \\
\cline { 2 - 4 } Controle & MCI & MCF & GMCA \\
\hline \multirow{2}{*}{ CIE } & 161,5 & 262,0 & 100,5 \\
& g/ninhada & g/ninhada & g/ninhada \\
& 100,5 & 151,1 & \\
& g/ninhada & g/ninhada & $88,9 \mathrm{~g} /$ ninhada \\
\hline
\end{tabular}

Tabela 4. Média \pm erro padrão de massa corpórea ( $\mathrm{g}$ ) da ninhada padronizada com oito filhotes de ratos da linhagem Wistar nos grupos controle (C) e consumo involuntário de etanol a 10\% (CIE). Análise estatística e teste de Tukey $(p<0,05)$.

\begin{tabular}{cc}
\hline Tratamentos & $\begin{array}{c}\text { Média } \pm \text { erro padrão da massa } \\
\text { corpórea da ninhada }(\mathbf{g})\end{array}$ \\
\hline Controle & $208,25 \mathrm{~g} /$ ninhada $\pm 9,88 \mathrm{~b}^{1}$ \\
CIE & $115,18 \mathrm{~g} /$ ninhada $\pm 9,29 \mathrm{a}$ \\
\hline
\end{tabular}

\footnotetext{
${ }^{1}$ Teste de Tukey $(p<0.0001)$.
} 


\section{DISCUSSÃO}

Foi possível constatarmos que a exposição do álcool no período gestacional e após o nascimento é prejudicial, interagindo tanto na formação do embrião, quanto no desenvolvimento do feto, segundo estudos anteriores (BROLESE, 2009). Resultados obtidos em nosso estudo diferem com os já obtidos no experimento de BROLESE (2009).

Observamos que as características fenotípicas, em dias do período hiporresponsivo ao estresse (SHRP), variam entre ambos os grupos dos filhotes. No grupo C (Controle) observou-se um melhor desenvolvimento nas características fenotípicas, como por exemplo, orelhas totalmente desenvolvidas no $5^{\circ}$ dia. Entretanto, no grupo CIE (Consumo Involuntário de Etanol) as orelhas se desenvolveram somente no $10^{\circ} \mathrm{dia}$.

BROLESE (2009) obteve resultados não significativos em relação à abertura dos olhos. No nosso experimento, a abertura total dos olhos foi diferentes no grupo $\mathrm{C}$ e no grupo CIE. Isso pode demonstrar a influência do consumo de etanol no desenvolvimento das características fenotípicas. Também foram observados atrasados no desenvolvimento dos dentes do grupo CIE comparados com o grupo C. Esse resultado confirma com os dados já descritos na literatura que diz respeito à interferência do álcool na erupção dos dentes incisivos e no desenvolvimento (BROLESE, 2009).

BROLESE (2009) não obteve nenhum resultado expressivo que se refere a filhotes raquíticos, enquanto o presente trabalho nos mostrou a possibilidade que o consumo excessivo de álcool durante a gestação pode causar indivíduos com baixo peso. BROLESE (2009) justifica que o baixo teor nutricional contido no leite materno é resultado da presença do etanol.

Segundo BROLESE (2009), os filhotes de roedores são capazes de processarem pequenas quantidades de etanol do líquido amniótico durante a fase gestacional, tornando - se assim tóxicas pra o feto e seu consumo excessivo pode levar o indivíduo a uma desnutrição secundária de uma má digestão e/ou má absorção dos nutrientes causando complicações 
MESSIAS, K.B. et al. Características fenotípicas de filhotes após consumo involuntário de etanol em rata da linhagem Wistar durante a prenhez. PUBVET, Londrina, V. 7, N. 2, Ed. 225, Art. 1492, 2013.

gastrointestinais associadas ao álcool. Por esse motivo, é comum na Síndrome Alcoólica Fetal (SAF) os animais descendentes nascerem com baixo peso.

MOLINA \& SOUZA (2010) relataram que o consumo de etanol na gestação demonstra a presença também no leite materno. Isso acontece porque o etanol interfere na liberação de ocitocina durante o período gestacional, reduzindo a quantidade de leite materno produzido pela rata no período neonatal, interagindo e influenciado sob o desenvolvimento fetal, contribuindo para as diversas más formações, induzindo uma Síndrome Alcoólica Fetal (SAF).

Portanto, diante das pesquisas anteriores e resultados adquiridos em nosso presente trabalho também foram possíveis verificar que o etanol é um agente agressor, sendo de grande importância uma maior atenção das gestantes, reconhecendo seus efeitos maléficos, recorrendo a acompanhamentos médicos durante este período.

\section{CONCLUSÃO}

Com base neste trabalho, concluímos que:

I - O álcool, quando administrado no período pré-natal, é uma droga de efeitos complexos.

II - A diversidade de fatores associados ao uso do álcool no período gestacional sugere medidas preventivas e uma maior atenção, como a não ingestão de bebidas alcoólicas, minimizando os efeitos que essa droga pode causar no feto.

III - O estado nutricional da mãe é um fator muito importante associado ao álcool na gestação. O controle nutricional é imprescindível para evitar problemas futuros.

IV - O presente trabalho mostrou que o álcool pode ocasionar prejuízos no desenvolvimento de animais cujas mães foram expostas ao álcool durante e após a gestação. 
MESSIAS, K.B. et al. Características fenotípicas de filhotes após consumo involuntário de etanol em rata da linhagem Wistar durante a prenhez. PUBVET, Londrina, V. 7, N. 2, Ed. 225, Art. 1492, 2013.

V - O consumo de etanol é prejudicial para a vida materno-fetal. Ressaltamos a importância de alguns cuidados no período gestacional como a abstinência alcoólica.

VI - É necessária a conscientização dos profissionais da saúde no que se diz respeito à SAF e à sua prevenção.

\section{AGRADECIMENTOS}

Ao Biotério e ao Laboratório de Química e Bioquímica das Faculdades Integradas Regionais de Avaré - Fundação Regional Educacional de Avaré.

\section{REFERÊNCIAS}

BARBOSA, C.A.; BARREIRO D. P.; SANTOS E. M.; I.R.VENEZIANI, E. M. LIBERATO. Uso excessivo de álcool: Patologia e suas influências na família e na sociedade. In: XIII ENCONTRO LATINO AMERICANO DE INICIAÇÃO CIENTÍFICA E IX ENCONTRO LATINO AMERICANO DE PÓS-GRADUAÇÃO - UNIVERSIDADE DO VALE DO PARAÍBA. ANAIS. São José dos Campos. p. 1 - 4. 2009.

BROLESE, G. Marcadores de desenvolvimento em filhotes de ratas expostas ao álcool no período pré-natal. 2009. 104 f. Tese (Mestrado em Neurociências) - Universidade Federal do Rio Grande do Sul, Porto Alegre.

FABBRI, C.E. Desenvolvimento e Validação de um instrumento de rastreamento do uso de bebidas alcoólicas do uso nocivo de álcool durante a gravidez (T - ACE). 2001. $89 \mathrm{f}$. Tese (Mestrado em Medicina Social) - Faculdade de Medicina de Ribeirão Preto, Universidade de São Paulo, Ribeirão Preto.

FRAJBLAT, M.; AMARAL, V.L.L.; RIVERA, E. A. B. Ciência em animais de laboratório. Revista Ciência e Cultura, São Paulo, v.60, n.2, p.44 - 46, 2008.

GIGLIOTTI, A.; BESSA, M.A. Síndrome de Dependência do Álcool: Critérios diagnósticos. Revista Brasileira de Psiquiatria, São Paulo v.26, (supl. 1): 11 - 13, 2004.

KREMER, R. Efeitos da separação materna e do alcoolismo no testículo de ratos ucha e uchb (bebedores voluntários de etanol a 10\%). 2007. 78 f. Tese (Mestrado em Biociências), UNESP, Botucatu, São Paulo.

LARANJEIRA, R.; PINSKY, I. ; ZALESKI, M.; CAETANO, R. I Levantamento nacional sobre os padrões de consumo de álcool na população brasileira. Revista Secretaria Nacional Antidrogas, p.76, Brasília, 2007.

LINS PESSOA J.H. Efeitos do álcool na gestante, no feto e no recém-nascido. Sociedade de Pediatria de São Paulo, p.25-35, 2010, São Paulo. 
MACDWELL, E. C. Alcoholism and the growth of white rats. Periodical station for Experimental Evolution, p. 428-231, New York. 1921.

MESSAS G. P.; VALLADA FILHO H.P. O papel da genética na dependência do álcool. Revista Brasileira de Psiquiatria, São Paulo, v.26, (supl 1): 54-58, 2004.

MOLINA, LML \& SOUZA, SR. Alcohol consumption during pregnancy: actions of nursing in prenatal care - a bibliographical stud. Revista cuidado é fundamental online ISSN 21755361, v.2, n.1, p. 659-663, 2010.

ROSSI, J.A.P.; SANTIAGO K.B.; MARTINS O.A. Estudo da Síndrome Alcoólica Fetal. Revista Eletrônica de Educação e Ciência (REEC), Avaré-SP, v.2, n.1, p.1-9, 2012.

VILELA, L.; MACHO, P.; ALMEIDA G. Consumo de álcool em adolescentes e psicopatologia associada. Revista tóxico dependências, v. 17, n. 1, p. 43-52. 2011. 